ENTREVISTA

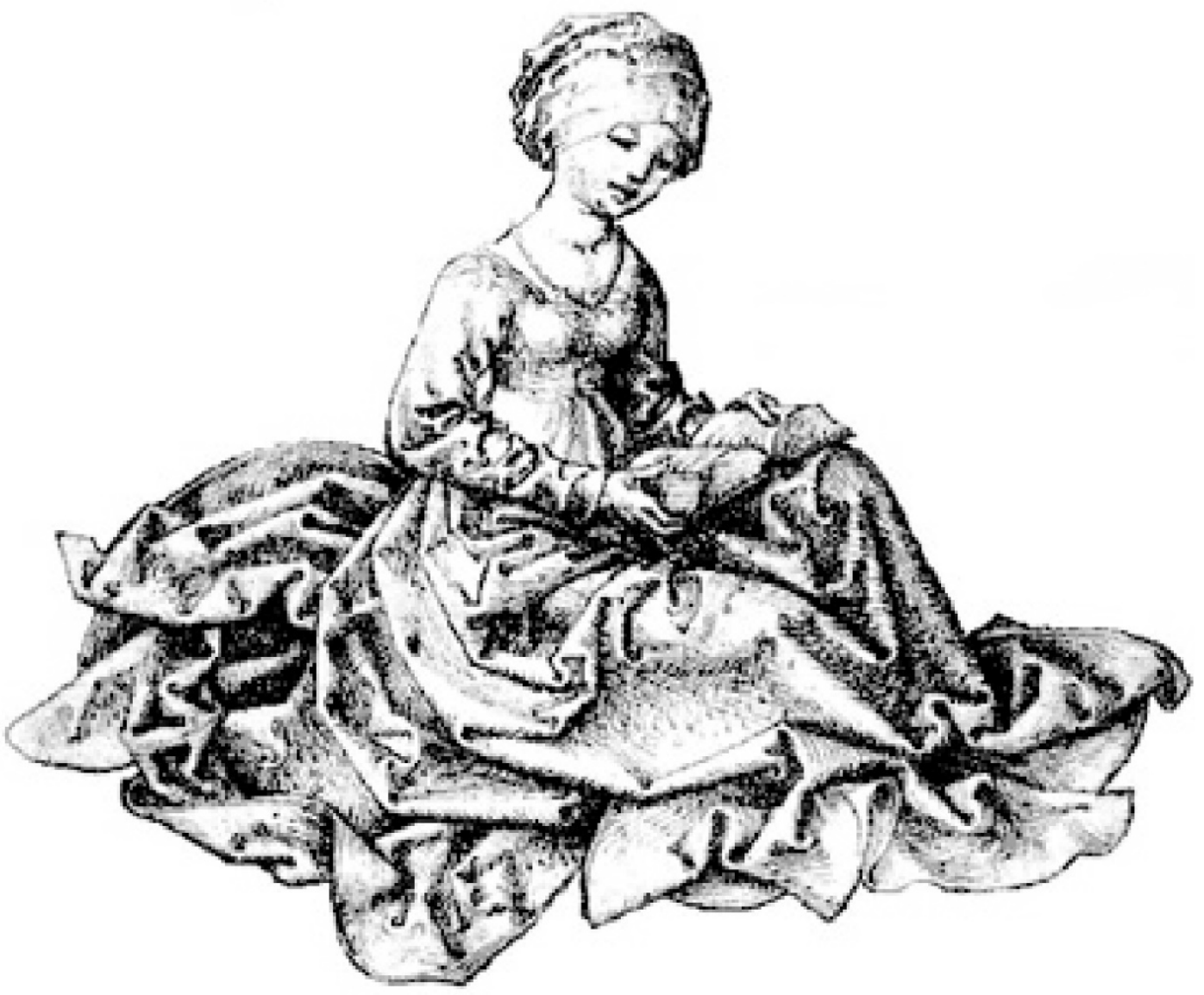





\section{INQUIETUDES TEÓRICAS E DESAFIOS CONTEMPORÂNEOS: ENTREVISTA COM ROGER CHARTIER}

\section{Ana Maria Veiga ${ }^{1}$ Guilherme Queiroz de Souza ${ }^{2}$}

Roger Chartier, historiador e sociólogo francês, destacou-se como um dos principais nomes do que se considera como a "quarta geração" da Escola dos Annales, inaugurada por Marc Bloch e Lucien Febvre com a publicação da revista Annales d'Histoire Économique et Sociale, em 1929.

A influência de Chartier sobre a historiografia brasileira teve início, de fato, entre o fim da década de 1980 e o início da seguinte, com a publicação do livro A História Cultural: entre práticas e representações. ${ }^{3}$ Por meio deste e de outros textos, ${ }^{4}$ este autor tornou-se incontornável para os estudos sobre representações que seguiam as linhas teóricas da corrente que ficou conhecida como Nova História Cultural.

Com o desenvolvimento de outros interesses de pesquisa, Roger Chartier passou a ser também uma referência nos estudos sobre a História do Livro, de sua circulação e das práticas de leitura, sobretudo na Idade Moderna. ${ }^{5}$ Além disso, seus trabalhos reflexivos sobre as inquietudes teóricas da historiografia também fomentam debates e sinalizam que as práticas historiográficas se encontram permanentemente instigadas pela teoria. ${ }^{6}$

${ }^{1}$ Doutora em História, com estágio doutoral na École des Hautes Études en Sciences Sociales. É professora do Departamento de História e do Programa de Pós-Graduação em História da Universidade Federal da Paraíba na área de Teoria da História. Tem pós-doutorado (PNPD) pelo Programa de Pós-Graduação Interdisciplinar em Ciências Humanas da UFSC. É editora da Sæculum Revista de História (PPGH/UFPB) e editora de divulgação da revista Estudos Feministas (REF).

2 Doutor em História pela Universidade Estadual Paulista (UNESP/Assis), com Mestrado e Graduação pela Universidade Federal de São João del-Rei. Professor adjunto de História Medieval da Universidade Federal da Paraíba. Membro da Associação Brasileira de Estudos Medievais (ABREM), Co-Fundador/Diretor da Roda da Fortuna - Revista Eletrônica sobre Antiguidade e Medievo e editor da Sæculum - Revista de História (DH/PPGH/UFPB).

${ }^{3}$ CHARTIER, Roger. A História Cultural: entre práticas e representações. Trad. Maria Manuela Galhardo. Lisboa: Difel, 1988; CHARTIER, Roger. A História Cultural: entre práticas e representações. Rio de Janeiro: Bertrand Brasil, 1990.

${ }^{4}$ Ver também CHARTIER, Roger. "O Mundo como Representação”. Estudos Avançados, 11(5), 1991, p. 173-191.

${ }^{5}$ Ver, por exemplo, CHARTIER, Roger. "Textos, Impressão, Leituras". In: HUNT, Lynn. A nova história cultural. São Paulo: Martins Fontes, 1992, p. 211-238; CHARTIER, Roger. A ordem dos livros. Leitores, autores e bibliotecas na Europa entre os séculos XIV e XVIII. Trad. Mary Del Priore. Brasília: Editora da UnB, 1994; CHARTIER, Roger. A aventura do livro: do leitor ao navegador. Trad. Reginaldo de Moraes. São Paulo: Editora da UNESP/Imprensa Oficial do Estado, 1999; CHARTIER, Roger. Leitura e leitores na França do Antigo Regime. Trad. Álvaro Lorencini. São Paulo: Editora da UNESP, 2004; CHARTIER, Roger. Inscrever e apagar: cultura escrita e literatura, séculos XI-XVIII. Trad. Luzmara Curcino Ferreira. São Paulo: Editora da UNESP, 2007.

${ }^{6}$ Ver CHARTIER, Roger. À beira da falésia: a história entre incertezas e inquietude. Trad. Patrícia C. Ramos. Porto Alegre: Ed. Universidade/UFRGS, 2002; CHARTIER, Roger. A história ou a leitura do tempo. Trad. Cristina Antunes. Belo Horizonte: Autêntica, 2009. 
Atualmente, seus investimentos intelectuais, como pesquisador da École des Hautes Études en Sciences Sociales (herdeira dos Annales) e professor do renomado Collège de France, estão voltados para o estudo das traduções. Para cada autor analisado, de Cervantes a Machado de Assis, o leque de traduções coloca, por vezes, o desafio de um novo idioma. Assim, ressaltamos que a entrevista que apresentamos, e que trata, como tema central, dos desafios contemporâneos da historiografia, foi realizada em português, no dia da conferência de abertura do XVIII Encontro Estadual de História (ANPUH-PB), proferida por Roger Chartier na Universidade Federal da Paraíba. $^{7}$

\section{$\operatorname{soc}$}

Sæculum: Quais são os problemas contemporâneos que se colocam como desafios para a historiografia?

Roger Chartier: Parece-me que os desafios fundamentais se vinculam com a capacidade da história de estabelecer um regime de verdade que seja diferente de outros regimes de verdade, por exemplo da memória ou da ficção e que se confrontam diretamente no mundo contemporâneo com o tema das falsificações, que desenhamos com a ideia de fake news, que é um conceito inventado pelo produto mais prolífico de fake news, o presidente dos EUA. Então, a primeira dimensão seria a de pensar que a história pode voltar à história das falsificações, porque é uma maneira de demonstrar a capacidade de conhecimento da história. Se falamos de falsificações é porque foram reconhecidas como tais, então uma falsificação que não se denuncia como falsificação não seria uma prova da capacidade da história. Mas, como sabemos, para o tempo atual, penso nas falsificações dos negacionistas, denunciadas por provas históricas por Vidal-Naquet, ${ }^{8}$ ou no ensaio fundamental de Carlo Ginzburg sobre talvez o primeiro exercício de uma crítica filológica, histórica, de Lorenzo Valla denunciando a falsa doação de Constantino ao Papa Silvestre. ${ }^{9}$ Há toda uma reflexão que se baseia sobre estudos de caso sobre as falsificações, podemos pensar o livro de Anthony Grafton, The Fortunes of "The Courtier", ${ }^{10}$ o livro de Caro Baroja [Las falsificaciones de la historia], sobre as falsificações na história da Espanha. ${ }^{11}$ É uma maneira de demonstrar no mundo contemporâneo que, em vários momentos do tempo, a história foi capaz de desvelar as falsificações. E se vincula com essa dimensão toda essa questão sobre a relação entre a história como escrita e a história como conhecimento, porque um elemento de desafio foi o de dizer que há uma verdade no romance, uma verdade na memória e que o regime de verdade da história não era diferente desses outros regimes de verdade. É a teoria, a tese

\footnotetext{
7 João Pessoa, 30 de julho de 2018.

${ }^{8}$ VIDAL-NAQUET, Pierre. Los asesinos de la memoria. Madrid: Siglo XXI Editores, 1994.

9 GINZBURG, Carlo. “Lorenzo Valla e a doação de Constantino". In: Relações de Força: História, retórica, prova. São Paulo: Companhia das Letras, 2002, p. 64-79.

${ }^{10}$ Encontramos este livro como sendo obra de Peter Burke, embora Anthony Grafton tenha feito uma resenha e comentários sobre ele, abordando a temática The Courtier. Cf. BURKE, Peter. The Fortunes of The Courtier: The European Reception of Castiglione's Cortegiano. Cambridge: Polity Press, 1995.

${ }^{11}$ CARO BAROJA, Julio. Las falsificaciones de la historia (en relación con la de España). Madrid: Seix Barral, Col. Biblioteca Breve, 1992.
} 
fundamental de Hayden White, que faleceu recentemente, e que encontra essa perspectiva de que não há diferenciação possível entre regimes de verdade. Podemos seguir um caminho aberto por Carlo Ginzburg, quando mostra que há, desde a referência retórica antiga, uma associação possível entre uma forma literária da escrita da história - quero dizer por literária o uso de estrutura narrativa e de figuras retóricas, de personificação das entidades abstratas -, não há uma oposição, senão uma relação possível entre essa forma retórica da escrita $e$ as operações próprias da historiografia, como o conhecimento do passado, essas operações que são, classicamente, a crítica dos documentos, a organização de uma estratégia de explicação e um regime de prova, que somente o texto vai ter controle sobre uma comunidade de saber. Então, no mundo de hoje, que está saturado pelas falsificações, propagandas, distorções do passado, a tarefa fundamental da história, parece-me, é a de reafirmar sua capacidade de produzir um conhecimento controlado, que se pode fazer, tanto com as reflexões sobre as falsificações, denunciadas como tais, quanto com uma reflexão sobre a articulação entre a operação científica da história e a forma retórica ou narrativa de sua escrita.

Sæculum: Sobre o seu trabalho, atualmente o senhor desenvolve uma pesquisa sobre traduções, certo?

Roger Chartier: Sim.

Sæculum: A tradução pode ser tomada como um "problema" ou por vezes ela pode ser uma solução, devido ao contato com novas teorias, por exemplo?

Roger Chartier: Pode ser um problema histórico e pode ser uma solução contemporânea. Problema histórico, porque me interesso pelo estudo de casos de tradução, como a de Cervantes para o inglês e para o francês, a tradução de livros que tiveram longa duração, traduzidos em muitas línguas, como Castiglione (Il Cortegiano [1528]), como Las Casas (Brevísima relación de la destrucción de las Índias [1552]), ou como Baltasar Gracián (Oráculo manual y arte de prudencia [1647]). É porque esses estudos de caso mostram as várias escalas sobre as quais é necessário trabalhar com a tradução, porque algumas vezes é a escala mínima de uma palavra, por exemplo, quando Castiglione inventou a palavra, quase um neologismo, "espresatura", para desenhar a característica fundamental do comportamento do cortesão; é uma palavra que os tradutores do século XVI devem confrontar, e encontrarão dificuldades para traduzir. No caso de Las Casas, a escala de trabalho é que o "mesmo texto" se localiza em vários contextos, muito diferentes: a denúncia da colonização espanhola, a ameaça dos espanhóis contra os protestantes, nos Países Baixos ou na Inglaterra, a guerra ou conflito entre Veneza e Espanha, e finalmente as guerras de independência dos países da América Latina. Então aqui não é um problema filológico da tradução, é a variação do sentido em relação ao contexto da tradução, o que se pode ver quando se analisa os prólogos das traduções do texto. E no caso de Gracián, parece-me um caso extraordinário, porque é um livro bem conhecido, o de Gracián. Norbert Elias utilizou este livro Oráculo manual y arte de prudencia como se fosse um manual para o que chama psicologia de Corte. A palavra Corte nunca aparece no livro de Gracián. O estatuto 
desse livro foi dado pela tradução francesa, que interpretou tudo isso como uma moral prática de Gracián, vinculada diretamente com a sociedade de Corte. É somente um exemplo para mostrar as várias escalas.

E para mim isso se localiza num projeto mais global, que é o de entender a mobilidade dos textos, uma ideia simples. Temos obras como Hamlet, Don Quixote de La Mancha, e para cada uma destas obras, uma multiplicidade de textos. E quais são as razões dessa pluralidade de textos para uma mesma obra? Pode ser a atribuição a um autor ou o anonimato, podem ser as variações do texto mesmo, do clássico, da filologia, as variantes de uma mesma obra, pode ser a materialidade de sua publicação, que dá uma resposta a diferentes horizontes de expectativas e podem ser, evidentemente, as leituras, dos leitores em diversos momentos do tempo, na história de longa duração da obra. A tradução é um outro elemento, porque a tradução pode ser de uma língua a outra, mas pode ser, algumas vezes, acompanhando ou não essa tradução linguística, uma migração de um gênero a outro - da crônica até a obra teatral, que são as obras históricas de Shakespeare. Ou do romance até obras teatrais, como as adaptações que estudei, mais particularmente, de Don Quixote de La Mancha. Então, parece-me um tema rico, um tema que permite também, como primeira resposta à questão da tradução como problema, mostrar esse disfarce cronológico. Cervantes foi imediatamente traduzido em francês, em inglês, em italiano e de maneira um pouco mais tardia em alemão. Shakespeare não foi traduzido para nenhuma língua até o final do século XVIII. A primeira tradução para o espanhol de uma obra de Shakespeare, a partir do texto original em inglês é de Moratín, Hamlet, de 1798. Então, a história da literatura pode comparar Shakespeare a Cervantes, foi um tema, um topos clássico particularmente durante o ano de aniversário de sua morte. Mas, se pensamos historicamente, vemos uma desigualdade radical entre a circulação, o conhecimento, a apropriação das obras. Então isso seria, entre muitos outros elementos, a resposta à ideia da tradução como problema, em si mesmo e também a serviço dessa reflexão sobre a pluralidade dos textos para uma mesma obra.

Agora, vocês diziam a "solução"? Sim, podemos pensar no mundo contemporâneo, cuja característica fundamental - apesar da palavra globalização se utilizar a torto e a direito - é ser um mundo fragmentado, um mundo do encerramento. Por várias razões. A primeira é a dificuldade, hoje, das traduções dos livros contemporâneos. A idade do ouro da tradução desapareceu, em todos os países as editoras são muito reticentes para traduções, considerando que é um custo alto para o livro e que, se a gente se interessa pelo tema de um livro em outra língua, deve conhecer essa outra língua. Então há uma dificuldade hoje para fazer circular uma forma de tradução, não só dos livros de ciências humanas ou de história. A consequência é que as bibliografias geralmente são monolinguísticas. Um caso extremo pode ser o norte-americano: se um livro não existe em inglês, não existe. Uma tarefa fundamental, como professor visitante de uma universidade na Filadélfia [University of Pennsylvania], é de convencer os estudantes de que há coisas que não foram nem escritas nem traduzidas para o inglês e que são, no entanto, fundamentais para o seu trabalho, inclusive se se dedicam a objetos que não são seus objetos. Mas não se lê um livro de história somente em relação com seu objeto. É o que eu dizia, há uma enorme literatura, por exemplo em crítica literária e filologia espanhola, ou de 
historiadores espanhóis, como Fernando Bouza e muitos outros, portugueses ou brasileiros, que nunca são traduzidos, porque se considera que se as pessoas se interessarem por esses livros é porque sabem o espanhol ou sabem o português.

Sæculum: Então a língua, essa barreira linguística, acabaria sendo um elemento de neocolonização?

Roger Chartier: Seria uma autocolonização, porque fechar-se a outras línguas é uma forma de colonização que vemos no sentido que para superar essa dificuldade, há uma tendência, mais limitada nas ciências humanas do que nas ciências exatas, de considerar que o inglês poderia ou deveria ser a língua de comunicação única. Mas para um historiador, escrever em uma outra língua, que não é a sua, é um exercício quase... se não impossível, pelo menos redutor, que empobrece a capacidade. Se voltarmos ao nosso primeiro ponto - a história como conhecimento -, o conhecimento se poderia transmitir em qualquer língua, mas também pela escrita, neste caso retórica, narrativa, metafórica, sem se vincular, evidentemente, com uma língua particular, como criação. Sempre com dificuldade, como a que mencionava para Castiglione ou Gracián, que é a da tradução.

Sæculum: Aproveitamos, então, para perguntar sobre a sua ligação com a língua portuguesa.

Roger Chartier: Ela me faz sofrer (sorri), a língua portuguesa. Seria um exemplo da história das línguas no final do século XX e começos do XXI. Minha primeira viagem ao Brasil foi em 1994, quando vim convidado pelo CPDOC, da Fundação Getúlio Vargas. Nos dois primeiros anos, dei as conferências em francês, que necessitaram de tradução. Mas a tradução é algo que, se possível, se deve evitar, pois com a tradução consecutiva a palestra nunca acaba, uma tradução simultânea é muito cara e, embora os tradutores sejam extraordinários, não conhecem nossos conceitos e traduzem para áreas diversas a cada dia. Então, a ideia era evitar isso. Foi possível, durante muitos anos, falando em espanhol, pois geralmente as pessoas entendiam no Brasil; mesmo assim, meu espanhol não era dos melhores. E, finalmente, um dia pensei que eu deveria fazer um esforço suplementar para ler e tentar escrever, ao menos cartas, em português, apesar de nunca ter frequentado ao menos uma hora de aula de português. É um português da prática. Essa história com a língua foi reforçada pela prática, porque esse tipo de trabalho que eu faço, no campo da cultura escrita, tem no Brasil uma pluralidade de interlocutores, não somente historiadores, mas também profissionais da educação. No Brasil, em comparação a outros países, em relação com as ciências sociais, com a história e com a crítica literária, é que as pessoas são mais abertas e mais próximas de uma abordagem sociológica, bibliográfica e material da literatura do que em outras tradições, como por exemplo a mais clássica da tradição francesa da história da literatura, principalmente a gente, que trabalha sobre o século XVII, pensa que há uma espécie de corrupção da estética se você propõe uma explicação mais sociológica, ou um interesse, como eu dizia, pela pluralidade de textos para uma mesma obra. Aí, um pouco como me aconteceu com a língua espanhola, comecei a trabalhar com alguns textos da tradição da língua portuguesa que são fundamentais para alguns dos projetos que discutimos. Dediquei um ensaio 
ao Don Quixote de La Mancha de Antônio José da Silva, um judeu que, depois de um segundo processo da Inquisição, fugiu de Lisboa. Ele escreveu para o Teatro das Bonifrates, um teatro de bonecos de Lisboa, uma série de obras e a primeira era Don Quixote de La Mancha. Estava dentro dos estudos que dediquei à circulação da obra de Cervantes.

$\mathrm{E}$, mais recentemente, não sei se vou me atrever a escrever, porque é um autor que tem uma bibliografia tão importante como a de Cervantes e Shakespeare, que é Machado de Assis. Mas o que me chamou a atenção é um romance que considero equivalente a Madame Bovary, que é Memórias póstumas de Brás Cubas. É uma maneira de entrar em uma série de análises que se vinculam uma com a outra; análise particularmente espetacular, neste caso, da variação do sentido da obra em relação com suas formas de publicação, entre o folhetim e o livro. Há um livro magnífico de Ana Cláudia Suriani ${ }^{12}$ uma colega que trabalha sobre isso, sobre essa transformação. Estas duas formas de publicação criam uma relação com as temporalidades da leitura que são totalmente diferentes. Na forma de folhetins dos jornais, o ritmo está imposto pela publicação; quando o texto está no livro, o leitor pode decidir como e quando quer ler. E também o formato implicava obrigações para o escritor, das quais se liberta quando pode passar o texto para uma forma de livro. Isso não é próprio somente de Machado, pois quase todos os romancistas do século XIX conheceram essa mesma experiência, da publicação fragmentada em forma de folhetim e depois uma reconstrução para o livro para uma mesma obra. Mas também há uma tensão de Machado, que é quase comparada ao texto do Século de Ouro Espanhol; há um mecanismo da publicação, da imprensa, da circulação dos textos, dos periódicos e também uma multiplicação das referências ao corpus canônico da literatura. Aqui há como uma autorreflexão sobre a cultura impressa dentro de um objeto que circula na forma impressa. E finalmente havia essa ideia... em Memórias póstumas de Brás Cubas há a teoria das "edições humanas". Diz Machado, Brás Cubas, que Pascal afirma que o homem é um "canudo pensante", mas não, é uma "errata pensante"; é a ideia de que os momentos da vida são como uma série sucessiva e a última será a mais correta e definitiva. Isso me chamou a atenção porque se vincula, no caso de Machado, com uma metáfora clássica, que existia desde o século XVI, XVII, que é a de comparar o corpo humano com um livro, de descrever o corpo como se fosse um livro, e o momento do delírio, nos começos do texto, descreve Brás Cubas como a Suma Teológica de Santo Tomás, todo o vocabulário era tradicional, e há muitos textos, como os de Shakespeare, os dos autores do Século de Ouro, que trazem essa ideia, do homem considerado como um livro e, algumas vezes, do livro considerado como um homem, porque tem alma $e$ corpo. No caso de Machado, se associa essa metáfora clássica com a teoria das edições humanas. E acho que eu havia encontrado isso em um epitáfio de Benjamin Franklin, quando jovem, que descreve o corpo como um livro, atacado pelos vermes e que a edição final, correta, do texto seria, evidentemente, a de depois da morte. Havia a associação já da metáfora clássica do corpo como um livro e a ideia da vida como uma série de edições sucessivas. Machado não diz que o leu, mas entendo que

\footnotetext{
${ }^{12}$ SILVA, Ana Claudia Suriani da. Linha reta e linha curva: edição crítica e genética de um conto de Machado de Assis. Campinas: Editora da Unicamp, 2003.
} 
sim, pois havia esse elemento suplementar de que o epitáfio de Benjamin Franklin foi recuperado no Brasil pelo espiritismo. Podemos pensar, no epitáfio de Franklin, a edição depois da morte em uma perspectiva cristã, mas era uma possibilidade de reencarnação. Este texto está citado em várias revistas espíritas como se Benjamin Franklin tivesse criado a teoria da reencarnação. Isso é um parênteses para mostrar meu interesse pela língua portuguesa, que posso eventualmente transformar num ensaio.

Sæculum: O medievalista francês Alain Guerreau causou certa polêmica ao afirmar que a "dupla fratura conceitual" do século XVIII teria sido prejudicial aos historiadores. Para ele, será sempre complicado aplicar categorias e conceitos modernos para o estudo das sociedades anteriores ao século XVIII. O que o senhor pensa sobre essa questão e sobre a utilização do seu conceito de "representação" reportado às sociedades antigas e medievais?

Roger Chartier: Evidentemente, é uma pergunta fundamental, sobre o controle do uso retrospectivo e anacrônico de categorias que foram forjadas ou definidas a partir de uma época histórica diferente. É um problema geral. Foi, por exemplo, o que discutimos até agora... esse problema fundamental: existe a Literatura antes da Literatura? Literatura é uma palavra que é designada, ou o que designamos hoje como Literatura, somente no século XVIII, e que se vinculava à noção de criação original, de individualização da escrita e da propriedade literária. Nada disso existe para o século XVI, XVII. Trata-se de inventar uma imitatio. Trata-se de uma propriedade que sempre é a propriedade do livreiro ou do impressor/ editor e a escrita coletiva era muito frequente, tanto para as obras teatrais como para os romances. Então, vemos que há aqui uma tensão, porque, se utilizamos Literatura para dizer que há uma Literatura medieval ou que há uma Literatura da primeira época moderna, estamos prisioneiros de um vocabulário difícil, talvez, de abandonar. Ao mesmo tempo, há um imediatismo de projetar o que se liga com a Literatura a partir do [século] XVIII, XIX, XX, sobre essas realidades tão diferentes.

$\mathrm{O}$ que estou dizendo aqui, para uma categoria cultural, evidentemente se podia dizer para uma categoria do tipo religioso ou de tipo socioeconômico. E era a observação de Alain Guerreau a propósito disso. ${ }^{13}$ Não há solução, parece-me, porque é difícil de imaginar um vocabulário totalmente diferente do vocabulário que usamos; e, ao mesmo tempo, soma-se a ideia de fazer lembrar, de recordar que, aplicado a uma realidade anterior ao momento de sua criação, deve-se sempre mostrar o que é diferente. Mas é um problema foucaultiano: existem loucos antes da Loucura? Fazemos uso de uma categoria trans-histórica em relação com descontinuidades históricas. Então, se se aplica a categoria de "representação", em um certo sentido a resposta é mais fácil, porque o primeiro uso da palavra representação, inclusive em inglês, é a efígie da soberania política através de um manequim, que está dotado das insígnias do poder real durante os funerais dos reis

\footnotetext{
${ }^{13}$ Ver, especialmente, GUERREAU, Alain. L'Avenir d'un passé incertain: quelle histoire du Moyen Âge au XXIe siècle? Paris: Le Seuil, 2001.
} 
da França e da Inglaterra; tem o livro de Kantorowicz, Os Dois Corpos do Rei. ${ }^{14}$ Neste momento extraordinário dos funerais, o corpo geralmente visível do rei está encerrado no catafalco, invisível. E o corpo que se vê é este corpo de uma efígie de cera e que tem o cetro, a coroa, o orbe da soberania, tudo isso. E se chamava "representação". Então, no mundo medieval, que se construiu através de uma prática ritual e através de uma realidade material, a definição da representação é algo que dá a ver uma ausência, uma abstração, porque aquilo que dá a ver são as insígnias do corpo místico e político do rei. E o que se vê tradicionalmente é o corpo físico de um indivíduo que pertence a uma dinastia monárquica. Então, a ideia de representação como estabelecendo uma relação entre o que representa e o que está representado, que é uma matriz essencial do uso dessa categoria, tem essa raiz na prática medieval dos funerais dos reis, da Inglaterra, em primeiro lugar, e da França. E, neste sentido, é uma noção que, menos que outras, seria profundamente anacrônica para a Idade Média, porque tem sua primeira definição nesse caso. Depois, evidentemente se enriqueceu, particularmente quando a representação não somente designava o que era o representante para algo representado, e ausente, mas quando havia a ideia de uma identificação entre a representação e o que representa. A ideia do indivíduo representando-se por si mesmo. Essa tensão se encontra em todos os dicionários de língua do [século] XVII - a representação como uma mediação ou a representação como uma exibição. Nesse caso de representação, parece-me que o problema teórico e historiográfico geral tem uma ilustração particular, porque também nos séculos XVI, XVII e XVIII, na estética clássica, a noção de representação é uma noção endógena.

Os historiadores algumas vezes impõem conceitos que são totalmente ausentes da realidade histórica que descrevem. É uma operação teórica completamente legítima; mudou de produção. $\mathrm{E}$, outras vezes, utilizando como conceito histórico uma categoria do tempo mesmo. Aqui, há um equilíbrio complexo entre o que a categoria definia no tempo de seu uso e os elementos que os historiadores incorporam nessa categoria quando a usam, não como uma citação do passado, mas como um instrumento analítico.

Sæculum: Quais seriam as principais tendências e "inquietações teóricas", de acordo com suas próprias palavras, da historiografia francesa que segue o legado dos Annales? Ainda é possível falarmos em uma "geração" intelectual nos dias atuais?

Roger Chartier: O problema que discutimos é histórico e historiográfico, em certo sentido. O problema historiográfico seria - nem todos podem ter a mesma opinião ou a mesma perspectiva - que hoje em dia, não somente na França, há como que um apagamento da tradição especificamente nacional epistemológica. Por um lado, evidentemente os Annales existiam como uma unidade metodológica quando tinha adversários, desde os anos 1930, de Febvre e Bloch, contra os ídolos da História, o político, o individual, o evento. E também quando se vinculou com uma revista (Annales), com uma instituição, que era em primeiro lugar a $\mathrm{VI}^{e}$ section de l'École Pratique des Hautes Études, quando foi fundada por Febvre depois da Segunda Guerra Mundial e transformada em École des Hautes Études en Sciences Sociales.

${ }^{14}$ KANTOROWICZ, Ernst H. Os Dois Corpos do Rei: um estudo sobre teologia política medieval. São Paulo: Companhia das Letras, 1998. 
Mas hoje essa vinculação não existe tanto. O Annales é uma revista plural, aberta, sem um paradigma dominante, porque talvez não estamos mais em um tempo em que há um paradigma dominante que se pode identificar com um grupo de historiadores e com uma revista particular. Parece-me que seria a mesma conclusão se vocês pensarem em Past and Present, que foi também, sem uma instituição, uma revista de expressão de um marxismo aberto, de uma forma de história social e que hoje pode ser uma excelente revista, mas tampouco é organizada com um paradigma intelectual único.

Então, o mundo contemporâneo está sem heranças; estamos constantemente fazendo referências a estes autores ou tradições. Hoje, a geografia da historiografia seria uma geografia diferente na qual cada tema, cada objeto - a história das cidades, a história econômica, a demografia histórica, a história da cultura escrita - se reconfigurou a partir do entrecruzamento entre tradições nacionais e metodológicas diferentes. Falou-se somente de modo próprio de campo de trabalho na História Cultural e, particularmente, na história da cultura escrita. Vê-se que, com certeza, há uma forte herança da tradição da história cultural francesa dos Annales, com uma dimensão forte de ênfase sobre a diferenciação social, com uma vontade - algumas vezes estatísticas - de estabelecer regularidades, mas que este campo foi profundamente transformado com o entrecruzamento entre esta tradição $e$ uma história da cultura escrita que tem como origem a paleografia, a codicologia do trabalho dos colegas italianos, de Armando Petrucci, que também faleceu recentemente. $\mathrm{E}$, evidentemente, da tradição da crítica textual anglo-americana tanto na forma bibliográfica como na forma do novo historicismo.

Então, parece-me que são estas formas de reconfiguração - a partir do objeto compartilhado de tradições diferentes - que caracterizam o mundo historiográfico contemporâneo, mais fortemente do que a sucessão das gerações, no caso de Annales, no caso de Past and Present, no caso da tradição da História das Ideias na Itália (grande herança de Franco Venturi). Seria a dimensão histórica da resposta. A dimensão historiográfica é talvez a que corresponda a esta forma, apesar do que dizia sobre o fim da circulação dos textos por falta de tradução. Aqui, estamos frente à hibridação de tradições que os historiadores podem controlar e domar por seu conhecimento das línguas.

O problema histórico seria esta atenção hoje sobre os mesmos fenômenos, mais historicamente a circulação, apropriação, hibridação, mestiçagem, que são próprios das Histórias conectadas, da história que dá ênfase a essas circulações, que podem ser circulações de homens, de populações, de produtos, de mitos, de textos. Então, essa proposta historiográfica tem um impacto forte sobre as histórias nacionais. No caso francês, o debate forte, historiográfico e ideológico, nasceu da publicação no ano passado de um livro coletivo - são 122 autores - de uma História Mundial da França. ${ }^{15} \mathrm{O}$ título escolhido por meu amigo e colega, Patrick Boucheron, era para opor esse tipo de análise que enfatizava os encontros da França com outras partes do mundo, a pluralidade étnica com relação às migrações, a crítica de uma ideia de uma "identidade francesa" permanente, trans-histórica. Ou também que algumas vezes destruía alguns mitos históricos, construídos a partir de uma escola primária do

${ }^{15}$ BOUCHERON, Patrick (dir.). Histoire mondiale de la France. Paris: Le Seuil, 2017. 
[século] XIX. Era uma tradução historiográfica para a história de uma nação particular, dessa aspiração a resgatar, compreender as formas de circulação, de hibridações que as histórias conectadas enfatizam. Isso se transformou, evidentemente, em uma polêmica ideológica, porque os meios que são ligados à ideia de uma identidade francesa permanente, que tem como consequência o rechaço do outro, consideram como uma corrupção, uma traição do romance nacional que deve, desde as origens, marcar, delimitar uma identidade francesa incorruptível, transhistórica.

Sæculum: O senhor acha que esse tipo de historiografia, que pensa essa França trans-histórica, pode ter relação com o diálogo, mesmo que não explícito, com os estudos pós-coloniais e decoloniais?

Roger Chartier: Sim, do lado do uso das histórias conectadas, que geralmente não foram aplicadas no território francês, inclusive quando os historiadores que praticam essa história são franceses; Serge Gruzinski e a história da Monarquia Católica, ${ }^{16} e$ historiadores de outras partes do mundo, como Subrahmanyam, que não era francês, mas que também foi professor na École des Hautes Études e, por pouco tempo, no Collège de France. O interessante, como vocês sugerem, é a aplicação desse modelo de histórias conectadas, que geralmente se vinculava como um Império, com presença em vários continentes, ou que se vinculava com estudos de espaços econômicos, mares, oceanos, inspirando uma volta sobre a história nacional, pode ser essa volta, como dizia, da "história mundial da França", de penetrações múltiplas de elementos estrangeiros na França e pode ser, no caso da tradição da história colonial, de uma tensão que se vê, por exemplo, em trabalhos sobre a escravidão ou em trabalhos sobre a saída da escravidão para Martinica, Guadalupe, os territórios franceses. Aqui, de novo, seria como uma ilustração desses espaços compartilhados, porque esse tipo de história está sendo massivamente praticada nos Estados Unidos, sobre a escravidão no Brasil e sobre as colônias hispânicas. E os que trabalham nesse campo estão nesse entrecruzamento de problemas, de técnicas, de abordagem, que não se limitam a um território particular, mas que são compartilhados para uma compreensão mais global. Então, parece-me, sim, que aqui encontramos, nesses encontros, uma maneira de fazer história, uma redefinição das configurações dessa prática.

Sæculum: Seria um certo retorno a uma história hoje dita global, não mais universal?

Roger Chartier: Sim, porque a categoria de história global pode ser muito enganosa, foi utilizada por esses livros, particularmente estadunidenses, em que a bibliografia é exclusivamente em inglês, de segunda mão. Essa é uma prática da história global, que é muito exigente. Então esse modelo de história global, como história universal, pode ter a definição filosófica das teorias da história pós-hegelianas, ou pode ser essa visão, a uma grande distância, mas baseada, escassamente baseada

${ }^{16}$ Ver, por exemplo, GRUZINSKI, Serge. "Les mondes mêlés de la Monarchie catholique et autres "connected histories'”. Annales, vol. 56-1, 2001, p. 85-117. 
sobre pesquisas precisas. Se for conservada a categoria da história global, parece-me que a proposta das histórias conectadas era diferente, era uma análise particular, meticulosa, específica, de formas de conexão, que suporia um espaço de conexão, mas um espaço libertado do Estado-nação, porque esse espaço pode ser entre culturas, civilizações, economias. E suporia, também, um conhecimento das línguas dos arquivos, e de uma produção historiográfica que teria as mesmas exigências de cientificidade que tradicionalmente a monografia histórica. É a razão pela qual a moda da história global pode ser muito, muito perigosa, no sentido de que nem todos os historiadores têm a capacidade deste conhecimento, de primeira mão, linguístico. É a razão da força de um historiador como Subrahmanyam, que conhece várias línguas da Índia, as línguas europeias e também o árabe. Desta maneira, há uma ideia de fragmentar a história global em uma série de histórias conectadas e de que cada um pode praticá-las, em relação com sua própria capacidade de controlar os instrumentos de trabalho.

Não se pode propor como modelo universal a história global, talvez porque seria apagar essa série de espaços de conexões, e também porque seria conduzir os historiadores a uma impossibilidade ou ao abandono dos critérios de pesquisa rigorosos que se haviam construído particularmente quando era o momento das monografias, do conhecimento dos arquivos, do conhecimento das línguas. E de os conduzir a uma forma de história mais superficial, porque não pode se referir diretamente às fontes primárias. Parece-me que há, aqui, uma necessidade de Império.

Sæculum: Professor Chartier, agradecemos a entrevista.

\section{$\operatorname{soc} 2$}

